\title{
Management of extensive subfoveal haemorrhage secondary to neovascular age-related macular degeneration
}

${ }^{1}$ Department of Ophthalmology, Medical University of Vienna,

Vienna, Austria

${ }^{2}$ Department of Ophthalmology, University of Zurich, Zurich,

Switzerland

Correspondence: C Prünte, Department of

Ophthalmology,

Medical University of

Vienna,

Waehringer Guertel 18-20, Vienna A-1090,

Austria

Tel: + 0043140400 7931; Fax: + 00431404007932

E-mail: christian.pruente@ meduniwien.ac.at

Received: 23 May 2008 Accepted in revised form: 29 July 2008

Published online: 29 August 2008

None of the authors have a commercial interest in any of the materials or methods mentioned
Abstract

Background To evaluate the clinical outcomes of subfoveal haemorrhages secondary to neovascular age-related macular degeneration (AMD), which were treated with intravitreal recombinant tissue plasminogen activator (rTPA)/gas and anti-vascular endothelial growth factor (anti-VEGF) drug or with an intravitreal anti-VEGF monotherapy.

Methods This is a retrospective pilot study.

Patients who received intravitreal rTPA/gas

and anti-VEGF injections $(n=20$,

bevacizumab or ranibizumab) were included in group A. Patients who refused prone positioning after rTPA/gas injections and were treated with an anti-VEGF monotherapy (bevacizumab) alone were included into group $B(n=10)$. Changes in baseline visual acuity (VA, Snellen), central retinal thickness (CRT) and haemorrhage size were analysed.

Results Mean baseline VA was $0.15 \pm 0.2$ and $0.25 \pm 0.17$ in groups $A$ and $B$, respectively.

At month 4, significant improvement in mean VA was observed in group A (mean difference: $+0.1 \pm 0.14 ; P=0.003)$, and a stabilization in group $B$ (mean difference: $+0.008 \pm 0.2$; $P=0.94)$. CRT decreased significantly by $70 \mu \mathrm{m}$ in group $A(P=0.001)$ and by $84 \mu \mathrm{m}$ in group $B$ $(P=0.03)$. The mean size of subfoveal haemorrhage in groups A and B was $20.2 \mathrm{~mm}^{2}$ and $19.1 \mathrm{~mm}^{2}$ at baseline and $0.0 \mathrm{~mm}^{2}$ and $2.0 \mathrm{~mm}^{2}$ at month 4 , respectively. The anti-VEGF treatmentrate was 1.6 in group $\mathrm{A}$ and 3.0 in group $B$.

Conclusion In patients with extensive subfoveal haemorrhage secondary to neovascular AMD, the combination therapy of rTPA/pneumatic displacement and anti-VEGF
S Sacu', E Stifter' ${ }^{1}$ PV Vécsei-Marlovits', S Michels², C Schütze ${ }^{1}$, C Prünte $^{1}$ and U Schmidt-Erfurth ${ }^{1}$ results in mean improvement of VA and stabilization of morphological parameters. If rTPA and pneumatic displacement combination is contraindicated, an anti-VEGF monotherapy may be performed to prevent further visual loss.

Eye (2009) 23, 1404-1410; doi:10.1038/eye.2008.267; published online 29 August 2008

Keywords: subfoveal haemorrhage; recombinant tissue plasminogen activator; gas; avastin; lucentis

Introduction

An extensive subfoveal haemorrhage is a serious complication of neovascular age-related macular degeneration (AMD) and is associated with poor overall prognosis. ${ }^{1-3}$ Vitreoretinal surgery to remove subretinal blood secondary to neovascular AMD is associated with various complications including damage of retinal pigment epithelium. ${ }^{4-9}$ Pharmacologically induced fibrinolysis does not significantly improve visual outcome. ${ }^{10,11}$ Treatment of subretinal haemorrhage without vitrectomy using an injection of recombinant tissue plasminogen activator (rTPA) followed by longacting gas is currently the most frequently used treatment approach. ${ }^{12}$ The ideal timing for this procedure was reported within the first 2 weeks after the onset of subfoveal haemorrhage. Nevertheless, the final visual outcomes of an intravitreous injection of fibrinolytic rTPA/gas for the pneumatic displacement of subfoveal blood seem to be limited by the progression of the underlying macular disease. In neovascular AMD with subfoveal blood, after the 
haemorrhage has been displaced from the central region and the area of the underlying choroidal neovascularization (CNV), photodynamic therapy with Verteporfin ${ }^{\mathbb{R}}$ was used to treat the $\mathrm{CNV}^{3}$ As the functional results of this treatment option were limited, other treatment concepts have to be evaluated.

Recently developed anti-vascular endothelial growth factor (anti-VEGF) antibodies for the treatment of CNV showed very good results with regard to efficacy and safety profile. In addition, an intravitreal and subretinal haemorrhage-clearing effect has been attributed to bevacizumab, an anti-VEGF drug. ${ }^{13,14}$ Therefore, combination of enzymatic (rTPA) and mechanical (gas) effects with an anti-VEGF drug may offer better functional and anatomical outcomes.

The aim of this study is to investigate the efficacy and safety of treating large subfoveal haemorrhage secondary to neovascular AMD with a combination of rTPA/gas and an anti-VEGF drug or with an anti-VEGF drug as monotherapy.

\section{Materials and methods}

This retrospective pilot study was performed on the clinical records of consented consecutive patients who had had extensive subfoveal haemorrhage secondary to neovascular AMD at the Department of Ophthalmology, Medical University of Vienna, Austria. In all patients, submacular haemorrhage was larger than 4 and smaller than 10 disc diameters within the arcades at baseline. To be eligible for this retrospective pilot study, patients had subretinal haemorrhage directly beneath the fovea. All patients had completed at least 4 months of follow-up. The study followed the tenets of the Declaration of Helsinki. The use of intravitreal anti-VEGF was approved by the local ethics committee. Before each injection of anti-VEGF drug, patients signed a standard institutional consent that described the potential risks and benefits of treatment.

Finally, 30 eyes of 30 patients who met the inclusion criteria were included in two groups for the analysis. Patients were treated with a combination of rTPA/ sulphur hexafluoride (SF6) gas, and an anti-VEGF drug was included in group A $(n=20)$. In patients refusing prone positioning after rTPA injections, or if rTPA/gas combination was contraindicated, intravitreal bevacizumab (Avastin ${ }^{\circledR}$ ) monotherapy was considered, and for the statistical analysis, data of this patient's group were included in group B.

At each visit, patients underwent Snellen visual acuity (VA) measurements to obtain best-corrected distance VA. An ophthalmic examination was performed consisting of a slit-lamp evaluation and a biomicroscopic fundus examination. Ocular imaging consisted of FA, fundus photography and optical coherence tomography (OCT, StratusOCT, Carl Zeiss Meditec Inc.). The area of submacular bleeding was assessed by FA or fundus photography. In some patients, indocyanine green angiography was additionally performed. Follow-up angiography was performed as needed for decisionmaking.

Optical coherence tomography imaging consisted of 6-diagonal fast, low-density (128 a-scans per diagonal) $6 \mathrm{~mm}$ scans and 6-diagonal slow, high-density (512 a-scans per diagonal) $6 \mathrm{~mm}$ scans performed at $30^{\circ}$ angles. The central retinal thickness (CRT) measurements were determined from the fast macular thickness maps calculated from the six low-resolution diagonal scans. The six high-density, high-resolution radial diagonal scans were used to qualitatively evaluate the macula and to determine if retreatment was needed. All intravitreal injections were performed using a standard protocol.

In group $\mathrm{A}$, before the treatment, acetazolamide (Diamox ${ }^{\circledR}$, Goldshield Pharmaceuticals Ltd, Darmstadt, Germany) was applied intravenously; dorzolamide hydrochloride and timolol maleate (Cosopt ${ }^{\mathbb{R}}$

Augentropfen, Merck Sharp \& Dohme Ges.m.b.H, Vienna, Austria) were given locally to reduce intraocular pressure (IOP). The eye was topically anesthetized by lidocaine and oxybuprocaine eye drops three times several minutes apart and a povidone-iodine (10\%) scrub was performed on the lids and lashes. Povidone-iodine (5\%) eye drops were then applied over the ocular surface and a sterile speculum was placed. Fifty micrograms of commercial rTPA solution (Actilyse, Boehringer, Ingelheim, Germany) in a volume of $50 \mu \mathrm{l}$ was injected slowly into the midvitreous cavity through a 30-gauge needle. After an aqueous tap to reduce IOP, $0.5 \mathrm{ml}$ of $100 \%$ SF6 gas was injected into the vitreous cavity. After IOP was measured, an additional aqueous tap was performed to reduce IOP if necessary. If ocular perfusion was normal and IOP was $<20 \mathrm{mmHg}$ (measured using Schiötz tonometry), an additional injection of an antiVEGF drug (Avastin ( $n=16$, bevacizumab, $1.0 \mathrm{mg}$ / $0.04 \mathrm{ml}$ ) or Lucentis $(n=4$, ranibizumab, $0.05 \mathrm{ml})$ ) was performed. Otherwise, application of an anti-VEGF was performed within 3 days after the initial procedure. After injections of rTPA/gas, patients were instructed to maintain prone positioning for $72 \mathrm{~h}$.

In group B, the intravitreal injection of $1 \mathrm{mg} / 0.04 \mathrm{ml}$ bevacizumab was performed following the standard protocol. $^{15}$

Indication for retreatment was persistent submacular blood or evidence for active CNV on the basis of OCT or FA. In case the patient required repeated injections $1 \mathrm{mg} / 0.04 \mathrm{ml}$ bevacizumab or $0.5 \mathrm{mg} / 0.05 \mathrm{ml}$ ranibizumab, dependent on the baseline treatment, were applied. The patients' blood pressure was routinely 
checked before each intravitreal injection. Postoperative treatment consisted of dexamethason and gentamicinsulfat (Dexagenta POS Augentropfen ${ }^{\circledR}$, Chroma Pharma,

Austria) eye drops 4 times a day for 1 week.

Statistical analyses were performed using SPSS statistical software (version 14.0 for Windows; SPSS Inc. Chicago, IL, USA) and included ranges, means, medians and 95\% confidence limits (CLs). For statistical analyses, decimal fractions of VA were converted to logMAR. Owing to potential selection bias, no statistical comparisons were performed between both study groups in this study. Within each study group, comparative statistics were determined using paired $t$-tests and paired Wilcoxon signed rank test. $P$-values $<0.05$ were considered to be statistically significant.

\section{Results}

In group $A, 20$ eyes of 20 patients (mean age: $75.3 \pm 8.5$ years) and in group B, 10 eyes of 10 patients (mean age: $78.1 \pm 6.7$ years) were followed for 4 months.

The mean period between symptomatic onset of submacular haemorrhage and the time of initial treatment was $7.1 \pm 3.8$ days in group $A$ and $12.9 \pm 12.6$ in group B.

\section{VA measurements and retreatments}

In group A (rTPA/gas/anti-VEGF), mean baseline VA was $0.15 \pm 0.2$ (Table 1; equivalent to $\log \mathrm{MAR} 1.1$ ). At month 4, VA improved in $80 \%$ (16 of 20) of the treated eyes with a mean VA gain of $0.16 \pm 0.12$, was stable in $5 \%$ ( 1 of 20 ), and decreased in $15 \%$ (3 of 20 ) of the treated eyes, with a mean VA loss of $0.1 \pm 0.0$. Table 2 shows frequency disribution of changes in VA from baseline. The range of VA changes from baseline is shown for each treated eye in Figure 1. Four months after the initial treatment, mean VA had significantly increased to $0.27 \pm 0.20$ ( $P=0.003$ compared with baseline; equivalent to $\log$ MAR 0.56 ; $95 \%$ CL: $(0.17 ; 0.36))$.

In this group, the intravitreal injection of anti-VEGF was performed at the same session in 3 eyes after rTPA/ gas application and in 17 eyes within 3 days after initial treatment. On average, mean of $1.6 \pm 0.9$ intravitreal anti-VEGF injections were performed during follow-up time.

Table 1 Study eyes: course in visual acuity, central retinal thickness and haemorrhage area through 4 months follow-up

\begin{tabular}{|c|c|c|c|c|}
\hline & Baseline & Month 4 & Change & P-value \\
\hline \multicolumn{5}{|c|}{ Group $A(\mathrm{n}=20)($ rTPA/gas/anti-VEGF $)$} \\
\hline \multicolumn{5}{|c|}{ Visual acuity, decimal fraction } \\
\hline Median \pm SEM & $0.1 \pm 0.04$ & $0.22 \pm 0.04$ & $0.1 \pm 0.03$ & $P=0.003^{\mathrm{a}}$ \\
\hline Mean \pm SD & $0.15 \pm 0.2$ & $0.27 \pm 0.2$ & $0.1 \pm 0.14$ & $P=0.003^{\mathrm{b}}$ \\
\hline $95 \% \mathrm{CL}$ & {$[0.06 ; 0.25]$} & {$[0.17 ; 0.36]$} & {$[0.04 ; 0.18]$} & \\
\hline \multicolumn{5}{|c|}{ Central retinal thickness, $\mu m$} \\
\hline Median \pm SEM & $278 \pm 18$ & $223 \pm 12$ & $-74 \pm 14$ & $P=0.001^{\mathrm{a}}$ \\
\hline Mean \pm SD & $289 \pm 58$ & $218 \pm 40$ & $-70 \pm 47$ & $P=0.002^{\mathrm{b}}$ \\
\hline $95 \% \mathrm{CL}$ & {$[250 ; 327]$} & {$[191 ; 245]$} & {$[-102 ;-39]$} & \\
\hline \multicolumn{5}{|c|}{ Max. area of submacular haemorrhage, $\mathrm{mm}^{2}$} \\
\hline Median \pm SEM & $20.6 \pm 1.4$ & 0 & & \\
\hline Mean \pm SD & $20.2 \pm 5.3$ & 0 & & \\
\hline $95 \% \mathrm{CL}$ & {$[17.1 ; 23.3]$} & 0 & & \\
\hline \multicolumn{5}{|c|}{ Group B $(\mathrm{n}=10)($ anti-VEGF monotherapy) } \\
\hline \multicolumn{5}{|c|}{ Visual acuity, decimal fraction } \\
\hline Median \pm SEM & $0.2 \pm 0.05$ & $0.2 \pm 0.05$ & $0.06 \pm 0.06$ & $P=0.84^{\mathrm{a}}$ \\
\hline Mean \pm SD & $0.25 \pm 0.17$ & $0.26 \pm 0.2$ & $0.008 \pm 0.2$ & $P=0.94^{\mathrm{b}}$ \\
\hline $95 \% \mathrm{CL}$ & {$[0.12 ; 0.38]$} & {$[0.14 ; 0.38]$} & {$[-0.14 ; 0.15]$} & \\
\hline \multicolumn{5}{|c|}{ Central retinal thickness, $\mu m$} \\
\hline Median \pm SEM & $292 \pm 26$ & $245 \pm 18$ & $-96 \pm 20$ & $P=0.03^{\mathrm{a}}$ \\
\hline Mean \pm SD & $325 \pm 82$ & $241 \pm 58$ & $-84 \pm 106$ & $P=0.04^{\mathrm{b}}$ \\
\hline $95 \% \mathrm{CL}$ & {$[266 ; 384]$} & {$[199 ; 283]$} & {$[-160 ;-7.9]$} & \\
\hline \multicolumn{5}{|c|}{ Max. area of submacular haemorrhage, $\mathrm{mm}^{2}$} \\
\hline Median \pm SEM & $20.3 \pm 2.1$ & $1.4 \pm 0.7$ & $-16.5 \pm 1.7$ & $P<0.001^{\mathrm{a}}$ \\
\hline Mean \pm SD & $19.1 \pm 5.5$ & $2.03 \pm 1.4$ & $-17.0 \pm 4.5$ & $P<0.001^{\mathrm{b}}$ \\
\hline $95 \% \mathrm{CL}$ & {$[13.9 ; 24.2]$} & {$[0.4 ; 3.6]$} & {$[-21.2 ;-12.8]$} & \\
\hline
\end{tabular}

Anti-VEGF, anti-vascular endothelial growth factor; rTPA, recombinant tissue plasminogen activator; SEM, standard error of mean; SD, standard deviation; 95\% confidence limits CL (lower confidence limit; upper confidence limit); data in bold, statistically significant $(P<0.05)$.

baired Student's $t$-test.

apaired Wilcoxon signed rank test. 
Table 2 Frequency distribution of changes in visual acuity from baseline

\begin{tabular}{|c|c|c|}
\hline $\begin{array}{l}\text { Change in visual acuity } \\
\text { from baseline to month } 4\end{array}$ & $\begin{array}{c}\text { Group } A(\mathrm{n}=20) \\
(r T P A / g a s / \\
\text { anti-VEGF) }\end{array}$ & $\begin{array}{c}\text { Group B }(\mathrm{n}=10) \\
(\text { anti-VEGF } \\
\text { monotherapy })\end{array}$ \\
\hline \multicolumn{3}{|l|}{ VA improvement } \\
\hline$\geqslant 2$-line increase & $6(30 \%)$ & $2(20 \%)$ \\
\hline$\geqslant 1$-line to & $6(30 \%)$ & $2(20 \%)$ \\
\hline$<2$-line increase & & \\
\hline$<1$-line increase & $4(20 \%)$ & $2(20 \%)$ \\
\hline No change & $1(0.5 \%)$ & 0 \\
\hline \multicolumn{3}{|l|}{ VA loss } \\
\hline$<1$-line decrease & 0 & $1(10 \%)$ \\
\hline$\geqslant 1$-line to & $3(15 \%)$ & $2(20 \%)$ \\
\hline$<2$-line decrease & & \\
\hline$\geqslant 2$-line decrease & 0 & $1(10 \%)$ \\
\hline
\end{tabular}

Anti-VEGF, anti-vascular endothelial growth factor; rTPA, recombinant tissue plasminogen activator.

In group B (anti-VEGF monotherapy), mean baseline VA was $0.25 \pm 0.17$ (Table 1 ; equivalent to $\log$ MAR 0.6). At month 4, VA improved in $60 \%$ (6 of 10) of the treated eyes, with a mean VA gain of $0.13 \pm 0.1$ (Table 2), and decreased in $40 \%$ (4 of 10) of the treated eyes, with a mean VA loss of $0.2 \pm 0.15$. The range of VA changes from baseline is shown for each treated eye in Figure 1. Four months after the initial treatment, mean VA was stable $(0.26 \pm 0.20 ; P=0.84$ compared with baseline; equivalent to $\log$ MAR $0.58 ; 95 \%$ CL: $(0.14 ; 0.38)$ ).

On average, mean of $3.0 \pm 0.8$ intravitreal anti-VEGF injections were applied in 4-week intervals.

\section{OCT retinal thickness measurements}

In group A (rTPA/gas/anti-VEGF), mean baseline CRT was $289 \pm 58$ (Table 1). CRT significantly decreased 4 months after the initial treatment (Table 1; $P=0.001$; mean difference to baseline: $-70 \mu \mathrm{m}$; 95\% CL: $(-102$; $-39 \mu \mathrm{m})$ ). At the end of follow-up time, mean CRT was $218 \pm 40$ (Table 1).

In group B (anti-VEGF monotherapy), mean baseline CRT was $325 \pm 82$ (Table 1). At the end of follow-up time, mean CRT had decreased to $241 \pm 58$ (Table 1; $P=0.03$; median difference to baseline: $-84 \mu \mathrm{m} ; 95 \% \mathrm{CL}$ : $(-106 ;-7.9 \mu \mathrm{m}))$.

\section{Area of subretinal haemorrhage}

The course of the area of submacular haemorrhage was analysed in both groups by evaluating fundus photography or fluorescein angiography.

In group $\mathrm{A}$, the area of the subretinal haemorrhage was $20.2 \pm 5.3 \mathrm{~mm}^{2}$ at baseline. At the end of follow-up time, no eye showed a residual subfoveal haemorrhage.
In group B, the area of the subretinal haemorrhage was $19.1 \pm 5.5 \mathrm{~mm}^{2}$ at baseline. At month 4 , the maximum area of subretinal haemorrhage was found to significantly decrease to $2.03 \pm 1.4 \mathrm{~mm}^{2}(P<0.001$ compared with baseline; Table 1).

\section{Fundoscopic changes}

The subretinal scaring and pigmentary reactions were evaluated on the basis of indirect ophthalmoscopy at month 4. Generally, in eyes treated with rTPA/gas and anti-VEGF combination, indirect ophthalmoscopy showed a yellowish lesion inferiorly outside the arcade and pigment irregularity or granular pigment atrophy and scaring in the macula. However, in eyes treated with anti-VEGF monotherapy, we observed small whitish lesions and subretinal fibrotic scaring in the macula.

\section{Complications and safety assessment group A}

A pars plana vitrectomy was performed in one eye due to vitreous haemorrhage observed 1 week after the initial treatment. At month 4, this patient showed a decrease in VA of 1 Snellen line compared with baseline (baseline VA: 0.6; month 4 VA: 0.5). No systemic adverse events were reported through month 4 .

\section{Group B}

Safety assessment was performed at each examination visit and revealed no adverse effects applicable to the intravitreal anti-VEGF injection. No serious ocular or systemic adverse events were reported through month 4 .

\section{Discussion}

The concept of anti-VEGF therapy has shown most promising results in phase III clinical trails for neovascular AMD. ${ }^{16-18}$ Therefore, combination of rTPA/ gas with an anti-VEGF drug, which directly affects the underlying neovascularization, may result in inactivation and regression of neovascularization and potentially lead to a lower risk for recurrent haemorrhage. In this retrospective case series, we evaluated the management of large subfoveolar haemorrhage secondary to $\mathrm{CNV}$ with a combination of intravitreous rTPA/gas and anti-VEGF. Additionally, we evaluated the clinical outcomes of intravitreal anti-VEGF for large subfoveal haemorrhages in neovascular AMD.

Published results of pilot studies using rTPA/gas procedure suggest improved visual outcome in selected patients, with only a small proportion (16\%) achieving postoperative VAs of 0.25 decimal (20/80 Snellen) or better. ${ }^{19-23}$ In our study, 10 of 20 eyes (50\%) treated with rTPA/gas and anti-VEGF and 3 of 10 eyes (30\%) treated with anti-VEGF monotherapy demonstrated 

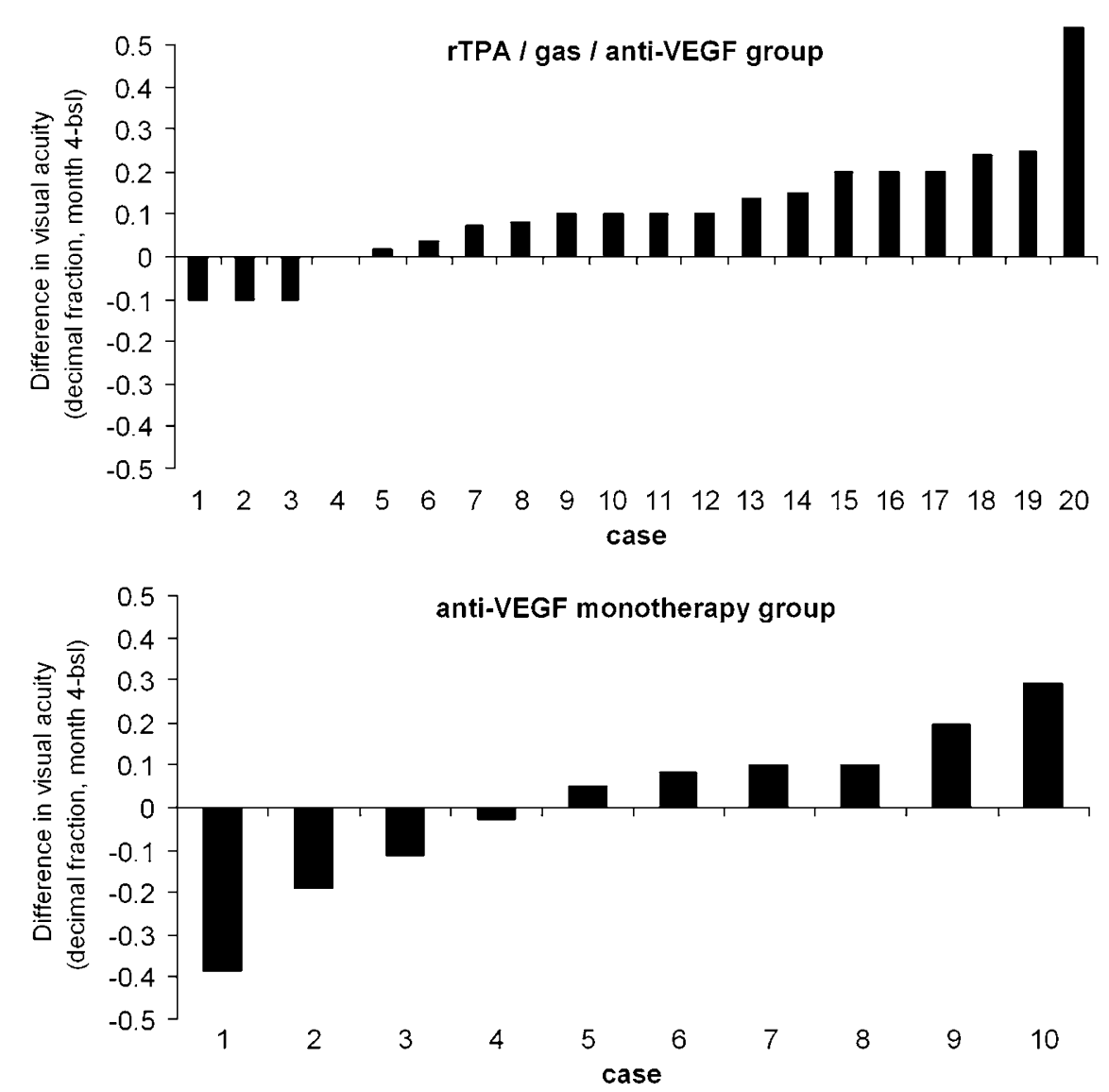

Figure 1 Change from baseline VA 4 months after initial treatment for each of the 20 evaluated eyes in rTPA/gas/anti-VEGF group (top) and for each of the 10 evaluated eyes in anti-VEGF monotherapy group (bottom).

a postoperative VA of 0.25 decimal or better. In a study by Hattenbach et al ${ }^{24}$ VA was improved 2 or more lines in approximately $30 \%$ of eyes (subretinal haemorrhage ranged from 0.25 to 30 disc areas) treated with rTPA/gas after a mean follow-up time of 6 months. In a retrospective case series, Hassan $e t a l^{25}$ observed a complete displacement of submacular blood (ranged in extent from 2 to 13 disc areas) in $100 \%$ of eyes after $\mathrm{rTPA} / \mathrm{gas}$. In another study by Hesse et al, ${ }_{11}^{11}$ intravitreous injections of 50-100 $\mu \mathrm{g}$ of rTPA/gas were performed in 11 eyes with submacular haemorrhage secondary to AMD. In their case series, VA improved by 2 lines in $45.5 \%$ of eyes. In our study, subretinal haemorrhage ranged from 4 to 10 disc areas and an improvement or stabilization of VA could be observed in $85 \%$ of eyes after rTPA/gas and anti-VEGF therapy and in $60 \%$ of eyes after anti-VEGF monotherapy.

Owing to inhomogeneous sample size and baseline characteristics, we did not perform any statistical comparison between both groups evaluated in the study. However, we observed a superior functional outcome in rTPA/gas and anti-VEGF group compared to anti-VEGF monotherapy group (Table 1). Briefly, patients in group A needed less retreatments (mean of 1.6 vs 3.0 anti-VEGF treatments) and showed better visual outcome (mean of +1 Snellen line vs 0 Snellen line, Table 1) compared with the patients in group B. A successful displacement of submacular haemorrhage that has resulted in rapid and easy resorption of residual subfoveal haemorrhage in group A seems to be an important prognostic factor. On the other hand, visual outcome might be better in group A, because the duration between the onset and the treatment was shorter than in group B. As mentioned in some reports, reduced functional outcomes can be attributed to submacular haemorrhage and other effects, for example, iron toxicity, shearing forces, and blockage of oxygen distribution. ${ }^{26,27}$

In a retrospective study, the treatment effect of intravitreal bevacizumab monotherapy was evaluated as treatment options for neovascular AMD with subretinal haemorrhage. ${ }^{28}$ In contrast to our study, the authors also included eyes with a submacular haemorrhage not directly beneath the fovea. They observed a visual improvement of $\geqslant 1$ and $\geqslant 3$ lines in 38\% (8 of 21) and 
9.5\% (2 of 21), respectively, and no significant difference in VA between patients with early therapy onset (within 2 weeks from symptomatic beginning) or late therapy onset ( $>2$ weeks from symptomatic beginning). They conclude that anti-VEGF monotherapy may be performed in patients refusing injections of rTPA/gas, in patients refusing prone positioning after injections, or if rTPA/gas combination is contraindicated due to an associated eye disease (eg, glaucoma). Furthermore, in eyes with $\mathrm{CNV}$ and large submacular haemorrhage not including the foveola, the rTPA/gas may not be performed when additional central visual loss may occur by displacing more blood into the central macular area. Also, in eyes with submacular haemorrhages older than 2 weeks and haemorrhages with a diameter of more than 10 disc areas, patient may be treated with an anti-VEGF monotherapy, as the effects of rTPA/gas injections are limited. ${ }^{10}$ However, the benefit of anti-VEGF treatment in this patient group needs to be shown.

In another retrospective pilot study, Meyer et $a l^{29}$ evaluated the treatment effect of rTPA/gas and antiVEGF combination in patients with a small subfoveal haemorrhage (1-3 disc diameters). They observed significant improvement of mean VA from 20/133 pretreatment to $20 / 86$ at 1 month and to $20 / 74$ at 3 months. ${ }^{29}$ None of the patients had reading VA before treatment, with VA below 0.3 , whereas $35 \%$ of their patients had reading VA at month $3(\geqslant 0.4)$. A successful inferior displacement of the subretinal haemorrhages was observed in 17 of 19 eyes. $^{29}$

Haemorrhage size and duration may serve as variables of prognostic importance after rTPA/gas. ${ }^{27}$ In our study, we do not identify preoperative or intraoperative predictors of visual outcome. The small sample size and relative homogeneity of our series with regard to haemorrhage size (4-10 disc areas) resulted in limited power to detect differences in outcome on the basis of preoperative variables.

We did not observe evidence of retinal or other intraocular toxic effects of rTPA correlating to the findings in the literature. In this study, no severe ocular adverse events following intravitreal anti-VEGF injection after rTPA/gas injection could be found.

To conclude, rTPA/expansible gas and anti-VEGF combination as well as the anti-VEGF monotherapy have shown promising results with regard to anatomical and functional outcomes in eyes with neovascular AMD and large subfoveal haemorrhage. However, significant benefit with regard to VA outcome was seen in the combination group. The outcome of our study indicates that the combination therapy may be recommended for the patients with acute ( $<3$ weeks) and extensive (4-10 disc areas) subfoveal haemorrhage secondary to neovascular AMD. If the rTPA/gas injection is contraindicated, an intravitreal anti-VEGF monotherapy could be performed to prevent further visual loss. Further prospective, controlled clinical trials will have to evaluate the effect of combination of pneumatic displacement and anti-VEGF therapy compared with rTPA and displacement therapy.

\section{References}

1 Avery R, Fekrat S, Hawkins B, Bressler N. Natural history of subfoveal subretinal hemorrhage in age-related macular degeneration. Retina 1996; 16: 183-189.

2 Bennett SR, Folk JC, Blodi CF, Klugman M. Factors prognostic of visual outcome in patients with subretinal hemorrhage. Am J Ophthalmol 1990; 109: 33-37.

3 Mozaffarieh M, Heinzl H, Sacu S, Wedrich A. In-patient management and treatment satisfaction after intravitreous plasminogen activator injection. Graefes Arch Clin Exp Ophthalmol 2006; 244: 1421-1428.

4 Ibanez HE, Williams DF, Thomas MA, Ruby AJ, Meredith TA, Boniuk I et al. Surgical removal of submacular hemorrhage. A series of 47 consecutive cases. Arch Ophthalmol 1995; 113: 62-69.

5 de Juan Jr E, Machemer R. Vitreous surgery for hemorrhagic and fibrous complications of age-related macular degeneration [case report]. Am J Ophthalmol 1988; 105: 25-29.

6 Vander JF, Federman JL, Greven C, Slusher MM, Gabel VP. Surgical removal of massive subretinal hemorrhage associated with age-related macular degeneration. Ophthalmology 1991; 98: 23-27.

7 Hanscom TA, Diddie KR. Early surgical drainage of macular subretinal hemorrhage. Arch Ophthalmol 1987; 105: 1722-1723.

8 Wade EC, Flynn HW, Olsen KR, Blumenkranz MS, Nicholson DH. Subretinal hemorrhage management by pars plana vitrectomy and internal drainage. Arch Ophthalmol 1990; 108: 973-978.

9 Haupert CL, McCuen BW, Jaffe GJ, Steuer ER, Cox TA, Toth CA et al. Pars plana vitrectomy, subretinal injection of tissue plasminogen activator, and fluid-gas exchange for displacement of thick submacular hemorrhage in age-related macular degeneration. Am J Ophthalmol 2001; 131: 208-215.

10 Schulze SD, Hesse L. Tissue plasminogen activator plus gas injection in patients with subretinal hemorrhage caused by age-related macular degeneration: predictive variables for visual outcome. Graefes Arch Clin Exp Ophthalmol 2002, 240: 717-720.

11 Hesse L, Schmidt J, Kroll P. Management of acute submacular hemorrhage using recombinant tissue plasminogen activator and gas. Graefes Arch Clin Exp Ophthalmol 1999; 237: 273-277.

12 Hesse L, Kroll P. Successful treatment of acute subretinal hemorrhage in age-related macular degeneration by combined intravitreal injection of recombinant tissue plasminogen activator and gas. Adv Ther 1997; 14: 275-280.

13 Spaide RF, Fisher YL. Intravitreal bevacizumab (Avastin) treatment of proliferative diabetic retinopathy complicated by vitreous hemorrhage. Retina 2006; 26: 275-278.

14 Soliman W, Lund-Andersen H, Larsen M. Resolution of subretinal haemorrhage and fluid after intravitreal 
bevacizumab in aggressive peripapillary subretinal neovascularization. Acta Ophthalmologica Scandinavica 2006; 84: 707-708

15 Aiello L, Brucker A, Chang S, Cunningham Jr ET, D'Amico DJ, Flynn Jr HW et al. Evolving guidelines for intravitreous injections. Retina 2004; 24: 3-19.

16 Gragoudas ES, Adamis AP, Cunningham ET, Feinsod M, Guyer DR. The Vegf inhibition study in ocular neovascularization clinical trial group. pegaptanib for neovascular age-related macular degeneration. $N$ Engl J Med 2004; 351: 2805-2816.

17 Rosenfeld PJ, Brown DM, Heier JS, Boyer DS, Kaiser PK, Chung CY, et al., MARINA Study Group. Ranibizumab for neovascular age-related macular degeneration. $N$ Engl J Med 2006; 355: 1419-1431.

18 Fung AE, Rosenfeld PJ, Reichel E. The International Intravitreal Bevacizumab Safety Survey: using the Internet to assess drug safety worldwide. Br J Ophthalmol 2006; 90: 1344-1349.

19 Lewis H. Intraoperative fibrinolysis of submacular hemorrhage with tissue plasminogen activator and surgical drainage. Am J Ophthalmol 1994; 118: 559-568.

20 Lim JI, Drews-Botsch C, Sternberg Jr P, Capone Jr A, Aaberg Sr TM. Submacular hemorrhage removal. Ophthalmology 1995; 102: 1393-1399.

21 Claes C, Zivojnovic R. Efficacy of tissue plasminogen activator (t-PA) in subretinal hemorrhage removal. Bull Soc Belge Ophtalmol 1996; 261: 115-118.

22 Kamei M, Tano Y, Maeno T, Ikuno Y, Mitsuda H, Yuasa T. Surgical removal of submacular hemorrhage using tissue plasminogen activator and perfluorocarbon liquid. Am J Ophthalmol 1996; 121: 267-275.

23 Moriarty AP, McAllister IL, Constable IJ. Initial clinical experience with tissue plasminogen activator (tPA) assisted removal of submacular haemorrhage. Eye 1995; 9: 582-588.

24 Hattenbach L-O, Brieden M, Koch F, Gümbel H. Intravitreal injection of rt-PA and gas in the management of minor submacular haemorrhages secondary to age-related macular degeneration [Article in German]. Klin Monatsbl Augenheilkd 2002; 219: 512-518.

25 Hassan AS, Johnson MW, Schneiderman TE, Regillo CD, Tornambe PE, Poliner LS et al. Management of submacular hemorrhage with intravitreous tissue plasminogen activator injection and pneumatic displacement. Ophthalmology 1999; 106: 1900-1907.

26 Glatt H, Machemer R. Experimental subretinal hemorrhage in rabbits. Am J Ophthalmol 1982; 94: 762-773.

27 Toth C, Morse L, Hjelmeland L, Landers M. Fibrin directs early retinal damage after experimental subretinal hemorrhage. Arch Ophthalmol 1991; 109: 723-729.

28 Stifter E, Michels S, Prager F, Georgopoulos M, Polak K, Hirn $\mathrm{C}$ et al. Intravitreal bevacizumab therapy for neovascular age-related macular degeneration with large submacular hemorrhage. Am J Ophthalmol 2007; 144: 886-892.

29 Meyer CH, Scholl HP, Eter N, Helb HM, Holz FG. Combined treatment of acute subretinal haemorrhages with intravitreal recombined tissue plasminogen activator, expansile gas and bevacizumab: a retrospective pilot study. Acta Ophthalmol 2008; 86(5): 490-494. 